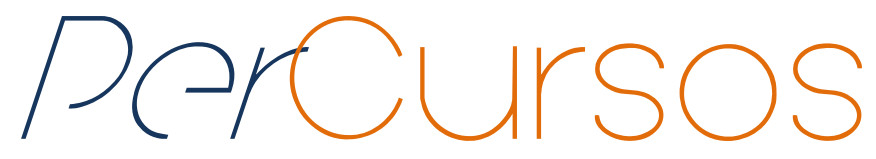

\title{
O modelo feminino na revista Fon-Fon! (1907-1958): a pedagogia da maternidade no Estado Novo ${ }^{1}$
}

\begin{abstract}
Resumo
O trabalho analisa a revista Fon-Fon! especificamente nos anos iniciais do Estado Novo (1937-1939). O objetivo é compreender a atuação da revista quanto aos conteúdos educativos e a forma adotada para atingir o público feminino. Nesse período, à mulher, foram prescritas as tarefas de governar o âmbito doméstico e de promover princípios morais, praticando e difundindo-os, em apoio à instituição familiar. A veiculação de conteúdos que envolviam a política, moda, culinária, conselhos às mães e às donas de casa, charges, anúncios publicitários, etc. dava o tom da sociedade que se pretendia construir, tendo como inspiração o modelo europeu de comportamento e cultura. Assim, parte-se do princípio de que a imprensa feminina constitui um importante artefato pedagógico-cultural na educação das mulheres, uma vez que são difundidas visões de mundo, modelos de feminino e ensinamentos maternos, influindo diretamente em sua formação subjetiva. $O$ texto organiza-se de modo, em um primeiro momento, a apresentar um breve levantamento dos aspectos essenciais da história da educação feminina no Brasil no início do século $X X$, seguido do exame da influência da imprensa na formação do pensamento social, com destaque à educação das mulheres. Por fim, far-se-á a apreciação de diversos conteúdos veiculados pela Fon-Fon! no recorte histórico ora delimitado.
\end{abstract}

\author{
Renata Franqui \\ Mestre em Educação pela \\ Universidade Estadual de \\ Maringá - UEM. \\ Brasil \\ renata.franqui@hotmail.com
}

\section{Marcília Rosa Periotto}

Doutora em Educação pela

Universidade Estadual de

Campinas - UNICAMP/SP.

Professora da Universidade

Estadual de Maringá - UEM.

Brasil

marciliaperiotto@yahoo.com.br

Palavras-chave: Educação feminina; Imprensa feminina; Revista Fon-Fon!.

\footnotetext{
${ }^{1}$ Projeto de pesquisa "A educação na província do Paraná e o debate modernizador na imprensa do século XIX: os jornais A Gazeta Paranaense (1882) e Província do Paraná (1876)", com apoio Coordenação de Aperfeiçoamento de Pessoal de Nível Superior - CAPES.

Este artigo é versão aprimorada do texto apresentado no VIII Congresso Brasileiro de História da Educação em Maringá, em 2015.
} 


\title{
The feminine model in Fon- Fon! magazine (1907-1958): the pedagogy of maternity in Brazilian New State
}

\begin{abstract}
This study specifically analyzes the Magazine Fon-Fon! in the years of the beginning of Brazilian New State (1937-1939). The aim of the study is to understand the representation of the magazine regarding the contents of education and the form adopted by it to reach the feminine public. During this period, to woman was prescribed the task of governing the domestic sphere and promote the moral principles, as well as practicing and spreading them, in support of the family institution. The publication of contents about politics, fashion, cooking, advice to mothers and housewives, cartoons, advertisements, etc., printed the tone that the society wanted to build, inspired in the European standard of behavior and culture. Therefore, from the understanding that women's press is an important pedagogical and cultural artifact in women's education, once ways to see the world, feminine models and maternal teachings are shared, influencing directly in their subjective formation. The text was organized for, at the first moment, presenting a brief survey of the essential aspects of the history of the feminine education in Brazil in the beginning of the twentieth century, followed by the review of the press on the formation of the social thought, with emphasis on women's education. At last, some contents published by Fon-Fon! will be analyzed at the historical period defined.
\end{abstract}

Keywords: Feminine education; Women's press; FonFon! magazine.

\section{Para citar este artigo:}

FRANQUI, Renata; PERIOTTO, Marcília Rosa. O modelo feminino na revista Fon-Fon! (1907-1958): a pedagogia da maternidade no Estado Novo. Revista PerCursos, Florianópolis, v. 17, n.33, p. 82 - 97 , jan./abr. 2016.

\section{DOI: $\mathbf{1 0 . 5 9 6 5 / 1 9 8 4 7 2 4 6 1 7 3 3 2 0 1 6 0 8 2}$}

http://dx.doi.org/10.5965/1984724617332016082 


\section{Introdução}

Inaugurada na cidade do Rio de Janeiro (RJ), no ano de 1907, a revistaFon-Fon! apresentou-se como um "Semanario alegre, politico, critico e esfusiante. Noticiario avariado, telegraphia sem arame, chronicaepidemica" ${ }^{2}$ (Fon-Fon,1907). Seu nome representava o som da buzina daquilo que havia mais moderno na capital da república, o automóvel, chegado recentemente ao país.

Sua criação insere-se em meio a um contexto histórico marcado por importantes mudanças sociais ocorridas nas décadas finais do século XIX - a Abolição da Escravatura, em 1888, e a Proclamação da República, no ano de 1890 -, bem como acontecimentos de proporções e influências globais no início do novo século, como a Primeira Guerra Mundial (1914-1918) e a Revolução Russa (1917), os mais significativos naquele início de século.

A partir do entendimento de que a imprensa configura-se como fonte histórica para os estudos de História da Educação, a revista Fon-Fon!,que circulou semanalmente no Rio de Janeiro até o ano de 1958, foi tomada como objeto de análise. O período delimitado para o estudo compreendeu os anos iniciais do Estado Novo, entre 1937 e 1939, e objetiva-se evidenciar a forma como o periódico se dirigiria ao seu público-alvo: a mulher da elite carioca.

A análise da revista realiza-se a partir de uma organização textual que pressupõe um breve levantamento dos aspectos essenciais da história da educação feminina no início do século XX no contexto brasileiro, seguida do exame da influência da imprensa no processo formativo do pensamento social, com destaque à educação das mulheres. Por fim, insere-se a apreciação de alguns conteúdos veiculados pela Fon-Fon! no recorte histórico ora delimitado, de modo a se evidenciar e ilustrar tais assertivas.

\footnotetext{
${ }^{2}$ Neste trabalho, optou-se por preservar a ortografia em vigência na época das publicações da revista FonFon!.
} 


\section{A educação feminina nas décadas iniciais do século XX}

A revista Fon-Fon! surgiu no mercado editorial do Rio de Janeiro no ano de 1907 , trazendo ares de renovação à imprensa periódica que circulava no período. Por se tratar de um periódico voltado para o público feminino, é importante compreender como se deram os processos formativos das mulheres ao longo dos tempos, fazendo-se necessário que se recorra à história.

A emancipação do Brasil em relação a Portugal, desde o ano de 1822, trouxe uma até então inédita preocupação com o destino da instrução da população brasileira. Essa discussão resultou na formulação na lei de 15 de outubro de 1827, elaborada durante o governo de D. Pedro I. A referida lei tratava, dentre outros aspectos, da educação que deveria ser ofertada às meninas, ao mesmo tempo em que sistematizava e buscava oficializar "a entrada da mulher na sociedade brasileira, ocupando inicialmente o lugar de estudante e depois de docente" (MONTEIRO; GATI, 2012, p. 3087).

Entretanto, a atuação feminina no magistério estava condicionada à sua conduta pessoal, devendo apresentar comportamentos adequados ao que se esperava da mulher naquele momento, muitas vezes supervalorizando as "condições morais, que se sobrepõem às condições de competências e formação intelectual" (MONTEIRO; GATI, 2012, p. 3088). Fúlvia Rosemberg (2012, p. 338) destaca que o incentivo à formação das professoras ligava-se estreitamente à ideia do magistério como um sacerdócio, pelo qual a mulher não deveria furtar-se de sua vocação inata para a maternidade.

Porém, nem sempre a defesa do acesso e progressão das mulheres à educação formal foi sustentada por razões emancipatórias para além da função doméstico-maternal. Durante os séculos XIX e XX, e mesmo nesse início do terceiro milênio, tem sido possível encontrar a justificativa de que se deve investir na educação da mulher porque "mulheres educadas são melhores mães". (ROSEMBERG, 2012, p. 338).

Adiante, destaca-se a importância da atuação de Gustavo Capanema enquanto esteve à frente do Ministério da Educação e Saúde no período de 1934 a 1945, atendendo a convite de Getúlio Vargas. A concepção de educação que deu tom ao seu ministério 
considerava que aquela deveria ter, por finalidade primordial, subsidiar a capacidade humana de adaptar-se às exigências da sociedade, bem como sua socialização.

Nesse contexto, a educação a ser ministrada deveria promover a construção de um novo ideal de homem, para um Estado Novo, empreendimento cultural e político que delegava, à educação, a tarefa de "socializar os indivíduos nos valores que as sociedades, através de seus segmentos organizados, querem ver internalizados" (BOMENY, 1999, p. 139).

As medidas adotadas por Capanema previam a diferenciação curricular para homens e mulheres, de modo a promover e salientar as competências que ele considerava inatas para cada um dos gêneros. Ao contrário do homem, que deveria ser preparado para o mundo público, à mulher era reservado um tipo de ensino que enfatizasse a formação para a vida doméstica e familiar.

Além disso, o Plano Nacional de Educação, publicado em 1937 (BRASIL, 1937), previa uma série de recomendações à educação feminina, sobretudo a partir de um currículo que privilegiava a disseminação de conteúdos voltados para o aperfeiçoamento dos conhecimentos afetos ao âmbito doméstico e para o exercício do magistério.

Vê-se, portanto, que o ensino voltado para o público feminino cumpria claramente o objetivo de propiciar, às mulheres, os conhecimentos necessários para que se capacitassem ao exercício do seu papel edificante no lar, atuando como boas mães, esposas dedicadas e exímias donas de casa. Somente assim, a mulher estaria apta para cumprir a tarefa de educar os filhos, atentando-se para torná-los futuros cidadãos, sensíveis à pátria e aos ideais propostos pelo Estado Novo.

No período do golpe do Estado Novo, o Brasil encontrava-se imerso em tensões sociais e políticas e, nesse contexto, o papel da mulher passou a ser visto como essencial para a consolidação desse novo modelo de Estado. A ela eram incumbidas a funções de governar o âmbito doméstico e portar-se como promotora dos costumes morais em apoio à instituição familiar, corroborando o poder político da classe dominante. 
Às mulheres a Era Vargas preparou, cuidadosamente, um projeto pedagógico, uma cartilha de retorno das mulheres ao lar, lugar de onde poderiam servir a pátria e a família ao mesmo tempo. Servindo a família, estariam, imediatamente, servindo a nação. Voltadas para os problemas domésticos, alienadas do contexto político, alheias aos problemas sociais e apenas com a função de mãe / esposa / educadora, não lhes era permitida qualquer afinidade ou semelhança com as funções masculinas ou da pátria. (NAHES, 2007, p. 38)

Dito isso, feito o breve levantamento da trajetória da educação feminina ao longo das décadas iniciais do século XX, abriram-se portas ao entendimento de que a formação das mulheres não se encerrava com o término do ensino secundário, mas passava a ocorrer por intermédio da leitura de revistas que se voltavam exclusivamente para esse fim. Tal é o caso da Fon-Fon!,revista dedicada primordialmente às mulheres da elite carioca, cumprindo uma função claramente pedagógica ao propiciar a formação continuada das mesmas por meio da veiculação de conteúdos afetos ao universo feminino.

\section{O caráter educativo da imprensa feminina}

Feito o levantamento dos principais desdobramentos da história da educação das mulheres no Brasil, é importante destacar que este trabalho parte do pressuposto de que os aprendizados não se restringem aos ambientes escolares e processos educativos sistematizados. Assim, as revistas e demais periódicos, dentre os quais a Fon-Fon!, estão inseridos em um conceito de educação de maior amplitude, o qual considera que a educação ocorre também por meio de "imagens, filmes, textos escritos, pela propaganda, pelas charges, pelos jornais e pela televisão [...]" (COSTA, SILVEIRA, SOMMER, 2003, p. 57).

Entende-se, portanto, que os segmentos femininos também foram educados por intermédio dos periódicos, ao passo que ensinavam as mulheres sobre como cuidar dos filhos, da casa e do marido, ou seja, os processos formativos, de modo geral, indicavam a conduta que se esperava da figura feminina naquele tempo histórico. Para além do âmbito doméstico e familiar, as revistas e jornais da época traziam vastas informações de 
moda, tendo em vista o assunto ser considerado de ampla aceitação no universo feminino.

Em um contexto histórico, marcado pela preocupação com a formação da identidade nacional brasileira, a capital francesa, Paris, surge como um modelo a ser seguido, tanto no que concerne aos hábitos e estilo de vida, quanto à moda e ao refinamento dos costumes. Assim, a camada social mais favorecida, também chamada de boa sociedade, buscava a civilização de seus costumes, bem como a eliminação dos ares coloniais, marcados pela rusticidade (RAINHO, 2002, p. 15), de modo a distinguir-se da sociedade comum.

Na primeira edição do ano de 1937, a revista inaugura a seção "Fon-Fon feminino", dirigida por Helene, passando a trazer, semanalmente, as novidades parisienses em relação à moda feminina e infantil, bem como os moldes para a reprodução das peças.

\footnotetext{
- Mas que é a Moda?

Um "instante de belleza" que senhoreia a emoção do mundo elegante, dominando, pela arte, pela surpresa, pela audacia e pelo colorido, o insatisfeito desejo feminino...

Se a Moda é isso, devemos interpretal-a com levesa, com agilidade e, como é natural, sem a monotonia dos padrões que se repetem... (FONFON,1937a, p. 41)
}

Além dos ensinamentos a respeito da moda, bem como a publicação dos moldes para reprodução das peças, a revista publicava uma grande variedade de textos e imagens que orientavam as mulheres sobre a maneira de comportar-se em seu casamento, incentivando a submissão, sujeição e anulação de si mesma em função de seu marido, características consideradas essenciais à esposa naquela época.

É o caso da matéria publicada pela coluna "Paginas do lar", em 7 de janeiro de 1939, sob o título de "Mulher e anjo", na qual Silvia Watteau oferecia conselhos às esposas: 
Não renuncies nunca, minha amiga, ao direito de ser anjo junto ao teu amado. De ser anjo, em vez de diabo; esposa, em vez de inferno; amiga, e nunca inimiga.

Sê confidente e não juiz. Não fiscalizes os actos de teu companheiro nem sigas seus passos. Humilha-te para amar; põe tua alma de joelhos para amar, mas não curves a cabeça para suspeitar...

De nada mais deves procurar saber, a não ser de uma coisa primordial: que és a dona e a rainha de tua casa sempre que saibas ser mulher e anjo... anjo e mulher...

Recebe, acolhe sempre bem e com encantadora simplicidade teu marido, teu companheiro e não renuncies nunca ao direito de ser sua socia em seus momentos difficeis, em suas dores, em suas lutas... Se teus filhos, não te esqueçastambem que elle é o pai de teus filhos...

Faz os rythmosda tua vida vibrarem sempre em harmonia com os da vida delle e nunca sejas hostil com os que amas, nem por ciume nem por amúos... Aquece em tuas mãos a mão daquelle que soffre e aprende a enxugar lagrimas, para, assim, estares certa de que és digna do mais nobre direito da vida: o direito de saber soffrer e saber amar... (FON-FON, 1939a, p. 8)

Na mesma seção, em texto publicado em 4 de setembro de 1937, a revista aconselhava a mulher que "não idolatre tanto o teu filho a ponto de esquecer o seu pae", alertando para o fato de que um "Homem que se julga esquecido, abandonado, é homem sempre mal humorado e enciumado" (FON-FON, 1937c, p. 18). Portanto, a revista afirmava que caberia à mulher a função de governar o lar, edificando as relações familiares a partir da qual estaria condicionada sua própria felicidade, conforme explicitado no texto da publicação:

Serás, então, duplamente feliz. Porque edificarás no sonho de teu filho a vigorosa fortaleza de seu futuro viril e não perderás nunca, nunca, o que ha de sensivel, de ingenuo e de fraco nessa alma grande mas infantil de teu companheiro, do teu verdadeiro homem... o marido criança... (FONFON, p. 18, 1937c)

O discurso sobre o modo de comportamento ideal da mulher-esposa também é reafirmado em matéria publicada em 4 de novembro de 1939, na "Tribuna dos radio 
ouvintes", na qual o Prof. Lima Castrioto aconselhava que os programas femininos de rádio, embora fossem realizados por homens, "pedagôgos especializados no assumpto", deveriam concentrar-se em "aperfeiçoar a mulher brasileira no culto das coisas dignas: o amôr conjugal, a educação dos filhos, o respeito ás coisas veneraveis, em summa - deve lembrar permanentemente á mulher brasileira o valor da dignidade feminina inatacavel" (FON-FON!, n. 44, 1939c, p. 31). Além disso, Lima Castriotto criticava as inspirações modernistas características do período, ao acusar o movimento de tentar abolir o sentimento respeitoso e a moral da sociedade: “[...] tenho a certeza de que ellas sabem que é mais constructivo ensinar a mulher a ser uma companheira dedicada, em vez de lhe requintar a vaidade, incentivando-a a ingressar no grupo das modernistas, allucinadas por todas as especies de illusões devastadoras" (FON-FON, 1939c, p. 31).

A partir do exposto, considerando-se que "[...] as revistas são, normalmente, o reflexo ideológico de sua época" (GOTTARDI; NAHES, 2006, p. 193), salienta-se a importância da análise dos conteúdos da revista, tendo-se em vista que estes contribuem para a compreensão dos sentidos e significados veiculados e vendidos pelo periódico, especialmente no período que concerne ao Estado Novo brasileiro, foco específico desta pesquisa.

\section{Revista Fon-Fon! E a pedagogia da maternidade}

As revistas são consideradas fonte histórica de "rastreamento do passado, ainda que com restrições" (MARTINS, 2003, p. 60) desde o século XIX. A veiculação de conteúdos que envolviam a política, moda, culinária, conselhos às mães e às donas de casa, charges, anúncios publicitários, entre outros, dava o tom da sociedade que se pretendia construir, tendo como inspiração o modelo europeu, especialmente parisiense, de comportamento e cultura, visto como sofisticado e mais adequado à elite social e política.

Assim, parte-se do princípio de que a imprensa feminina constitui um importante artefato pedagógico-cultural na educação das mulheres, uma vez que, por meio de sua 
leitura, são difundidas visões de mundo, modelos de feminino e ensinamentos maternos, influindo diretamente na formação subjetiva das mulheres.

A publicação veiculada na FonFon! em 2 de janeiro de 1937 trazia a coluna intitulada “Conselhos às Mães”, na qual o médico Rinaldo de Lamare ${ }^{3}$ ensinava a maneira considerada correta de se lidar com a saúde física e emocional dos filhos, instruindo as mães leitoras da revista a cumprirem sua função social para a época.

[...] Criar um filho é tarefa bem difícil, educar, então, é tarefa difficilima. Nós medicos pediatras temos oportunidade de ver crianças bem criadas, mas bem "malcriadas". Bem criadas do ponto de vista physico e mal criadas do ponto de vista social e moral.

Não são, como poderia parecer, a principio, os filhos de lares mais modestos os unicos que incorrem na falta citada. Ás vezes filhos de fortuna e do bem estar estão perfeitamente catalogados entre elles.

[...] O processo de educar que certos paes usam e ás vezes a benevolenciaexaggerada por um excesso de zelo, ou a severidade extrema por uma autoridade paterna, grande parte das vezes mal comprehendida, são as unicasresponsaveis por desatinos, que os filhinhos de hoje, rapazes de amanhã, possam commetter.

[...] Aqui está, em angulo bem aberto, o nosso programma. Que possamos concorrer, por todos os meios passiveis, pelo bem, pelo progresso e pela perfeição da criança de hoje, que é o Brasil de amanhã, e nos sentiremos recompensados (FON-FON, 1937a, p. 54).

No dia 18 de junho de 1938, Rinaldo de Lamare, em nome da revista, publicava um texto com conselhos de ordem prática, tratando especificamente dos cuidados necessários para a tornar a mulher apta para amamentação. Dizia o médico que

[...] as nutrizes devem ter toda tranquillidadepossivel, e serem tratadas com o maximo cuidado e mesmo carinho. Estas palavras devem ser dirigidas sobretudo aos maridos... A preocupação da educação moderna com "Escola de Mães" deveria ser extendida, também, pelo menos numa

\footnotetext{
${ }^{3} \mathrm{O}$ médico pediatra brasileiro, Rinaldo Victor de Lamare, nasceu na cidade de Santos-SP em 2 de janeiro de 1910 e faleceu no Rio de Janeiro-RJ em 28 de abril de 2002. Durante sua vida, realizou um extenso trabalho de pesquisa sobre cuidados infantis e aleitamento materno, publicando o famoso livro "A vida do bebê", publicado inicialmente em 1941, mas que constitui objeto de leitura das mães brasileiras até a atualidade.
} 
lição, ao sexo forte. Exige-se tudo para uma mulher ser mãe, e, no entanto para o pae, nada. (FON-FON, 1938, p. 12)

De maneira explícita, e em nome de uma educação infantil que primasse pelo futuro da nação, o médico aconselhava às mães o melhor trato com os cuidados infantis, demonstrando a responsabilidade da mulher em educar seus filhos à medida que eles seriam o futuro e os encarregados do progresso do país. A respeito da preocupação de cunho higienista, pertinente ao governo varguista, a qual caracteriza o início do século XX, Martins (2008) afirma que

A família e a criança passam a ser vistos como agentes políticos, promessas do futuro da nação e da raça. [...] Por fim, o agente considerado mais importante e vital para que essas medidas protetoras tivessem eficácia é a mãe. [...] Cabia aos médicos, apoiados pelo Estado e pela iniciativa privada, orientar as mães, conduzi-las pelo reto caminho da puericultura, disciplinando-as e fiscalizando as suas práticas. (MARTINS, 2008, p. 140)

Nesse momento, a ideia do asseio estava diretamente relacionada a uma boa educação, sendo uma forma de clara distinção social (SANT'ANNA, 2011, p. 292). Em texto intitulado "Alimentação artificial dos bebe's", publicado em 11 de fevereiro de 1939, FonFon! aconselhava sobre a necessidade de as mães buscarem informações a respeito da educação e saúde infantil, salientando que

A hygiene e a puericultura indicam as regras para a racionalização da alimentação, de summaimportancia sobretudo nos casos de alimentação artificial dos bebés. As mães devem, pois, procurar conhecer livros existentes sobre estes assumptos, bem como frequentar os departamentos de hygiene infantil para receber as instrucçõesnecessarias. Assim procedendo diminuem as possibilidades de erro e concorrem para a criação de filhos fortes e belos.(FON-FON, 1939b, p. 13)

Em concordância, no dia 24 de abril de 1937, a revista anuncia a publicação da terceira edição do livro de Martinho da Rocha, intitulado "Cartilha das Mães", cuja 
importância , dois anos antes, havia exaltado, atribuindo ao seu autor, o médico Martinho da Rocha, as honras de uma "obra patriotica, humana e magnifica a dos que defendem a criança".

Elle prestará ao povo brasileiro, através das mães brasileiras, um serviço inestimavel, maior do que dezenas de leis que ninguem cumpre. $\mathrm{E}^{\prime}$ um verdadeiro cathecismo maternal, crystalino nos seus conceitos, singelo nas suas rapidas apreciações, substancioso na sua doutrina, preciso nas suas regras. (FON-FON, 1935, p. 41)

Esse discurso de proteção à infância se completa com a publicação de uma grande diversidade de anúncios publicitários de produtos de higiene pessoal e remédios voltados aos cuidados com as crianças.

Em dezembro de 1937, a revista publicou um anúncio de um medicamento para desinfecção de ferimentos, podendo ser usados por adultos ou crianças. O texto da publicidade dirige-se especialmente às mães, indicando que essas "tem o dever sagrado de manter a máxima hygiene no quarto dos seus filhinhos". Além disso, ao afirmar que “Milhares de donas de casa, em todos os Paizes cultos, dão preferencia ao 'LYSOL", o texto publicitário reafirmava a vinculação da maternidade com a figura de dona de casa, contribuindo para a legitimação do ideal feminino comum à época. 


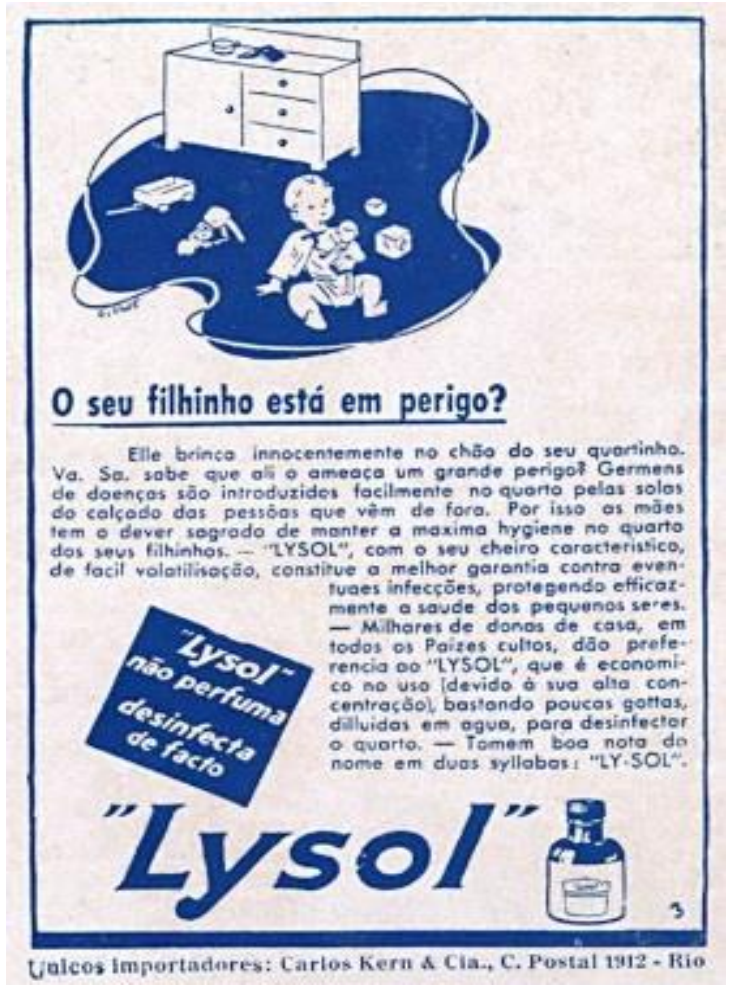

Fonte: Biblioteca Nacional, Fon-Fon, 1937, p. 32.

Entende-se que a publicidade reproduz um discurso que já circulava no meio social, a partir do princípio de que "os anúncios publicitários ensinam modos de conduta para pessoas de todas as faixas etárias, delimitando espaços, traçando caminhos, configurando identidades" (SABAT, 2007, p. 149). Assim, a análise dos conteúdos veiculados em alguns exemplares publicados nos anos de 1937 a 1939 pela Fon-Fon! fornece pistas para a compreensão das relações comportamentais da sociedade de então, possibilitando o trabalho de construção de sentidos no social por meio de elementos diversificados de expressão (BRITES, 2000, p. 164).

\section{Considerações finais}

A partir do estudo, é possível entender o propósito da revista Fon-Fon! de retratar a vida privada da sociedade brasileira no início do século $X X$, sobretudo em relação à classe alta, também denominada de boa sociedade. Por meio de um conteúdo permeado de humor e, não raro, por uma ácida crítica social, a revista assumiu papel significativo na 
formação da opinião pública, servindo como espaço privilegiado para o debate e produção ideológica no período, sob a perspectiva da classe burguesa.

Aliando-se à proposta educacional empreendida pelo Ministério da Educação no período, sob a tutela do ministro Gustavo Capanema, a ação político-educativa, presente no periódico, ocorria na veiculação de conteúdos que deixavam claro o propósito almejado: contribuir na formação das mulheres da elite carioca a partir da disseminação de conteúdos educativos - de maneira explícita ou implícita -, que inculcassem comportamentos, valores e ideias para as mulheres consonantes ao ideal feminino cogente ao período.

Nesse sentido, compreende-se que o estudo e análise dos conteúdos veiculados pela revista Fon-Fon!, durante os anos iniciais do Estado Novo brasileiro, permitem vislumbrar o ideal de feminilidade que se esperava das mulheres do período, de modo a formá-las para o exercício de um papel social delimitado, qual seja, atuarem como promotoras dos ideais de moralidade e saúde, contribuindo para a formação das crianças, aquelas que ser tornariam novos cidadãos brasileiros e, por conseguinte, os futuros dirigentes da nação.

\section{Referências}

BOMENY, Helena Maria Bousquet. Três decretos e um ministério: a propósito da educação no Estado Novo. In: PANDOLFI, Dulce (Org.). Repensando o Estado Novo. Rio de Janeiro: Ed. Fundação Getúlio Vargas, 1999. p. 137-166.

BRASIL. Ministério da Educação e Saúde Pública. Plano Nacional de Educação. Rio de Janeiro: Imprensa Nacional, 1937.

BRITES, Olga. Crianças de revistas (1930/1950). Educação e Pesquisa. São Paulo, v.26, n.1, p. 161-176. jan./jun.2000.

COSTA, Marisa Vorraber; SILVEIRA, Rosa Hessel; SOMMER, Luiz Henrique. Estudos culturais, educação e pedagogia. Revista Brasileira de Educação.n. 23. p. 36-61, maio/jun./jul./ago.2003. 
FON-FON! Rio de Janeiro, abril, n. 1, 1907. 36 p. Disponível em:

<http://objdigital.bn.br/acervo_digital/div_periodicos/fonfon/fonfon_1907/fonfon_1907_0 01.pdf >. Acesso em: abr.2015.

FON-FON! Rio de Janeiro, março, n. 11, 1935. 63 p. Disponível em: $<$ http://objdigital.bn.br/acervo_digital/div_periodicos/fonfon/fonfon_1935/fonfon_1935_01 1.pdf >. Acesso em: nov.2015.

FON-FON! Rio de Janeiro, janeiro, n. 1, 1937a. 51 p. Disponível em: <http://objdigital.bn.br/acervo_digital/div_periodicos/fonfon/fonfon_1937/fonfon_1937_0 01.pdf>. Acesso em: abr.2015.

FON-FON! Rio de Janeiro, abril, n. 17, 1937b. 67 p. Disponível em: $<$ http://objdigital.bn.br/acervo_digital/div_periodicos/fonfon/fonfon_1937/fonfon_1937_01 7.pdf>. Acesso em: nov.2015.

FON-FON! Rio de Janeiro, setembro, n. 36, 1937c. 67 p. Disponível em: <http://objdigital.bn.br/acervo_digital/div_periodicos/fonfon/fonfon_1937/fonfon_1937_0 36.pdf >. Acesso em: nov.2015.

FON-FON! Rio de Janeiro, junho, n. 25, 1938.58 p. Disponível em: $<$ http://objdigital.bn.br/acervo_digital/div_periodicos/fonfon/fonfon_1938/fonfon_1938_0 25.pdf>. Acesso em: nov.2015

FON-FON! Rio de Janeiro, janeiro, n. 1, 1939a. 64 p. Disponível em: <http://objdigital.bn.br/acervo_digital/div_periodicos/fonfon/fonfon_1939/fonfon_1939_0 01.pdf>. Acesso em: abr.2015.

FON-FON! Rio de Janeiro, fevereiro, n. 06, 1939b. 51 p. Disponível em: < http://objdigital.bn.br/acervo digital/div periodicos/fonfon/fonfon 1939/fonfon 1939 006.pdf f $>$. Acesso em: nov.2015.

FON-FON! Rio de Janeiro, novembro, n. 44, 1939c. 50 p. Disponível em: $<$ http://objdigital.bn.br/acervo_digital/div_periodicos/fonfon/fonfon_1939/fonfon_1939_0 44.pdf $>$. Acesso em: nov.2015

GOTTARDI, Ana Maria; NAHES, Semírames. Revista Fon-Fon: a imagem da mulher no Estado Novo (1937/1945). Comunicação: Veredas. ano V, n. 5, nov./2006. Disponível em:<http://www.unimar.br/publicacoes/comunicacao05.pdf>. Acesso em: abr.2014.

MARTINS, Ana Luiza. Da fantasia à história: folheando páginas revisteiras. Revista NERA (UNESP). São Paulo, v. 22, p. 59-79, 2003. 
MARTINS, Ana Paula Vosne. "Vamos criar seu filho": os médicos puericultores e a pedagogia materna no século XX. História, Ciências, Saúde. v. 15, n. 1, p. 135-154, jan./mar.2008.

MONTEIRO, Ivanilde Alves; GATI, Hajnalka. A mulher na história da educação brasileira: entraves e avanços de uma época. In: SEMINÁRIO NACIONAL DE ESTUDOS E PESQUISAS 'HISTÓRIA, SOCIEDADE E EDUCAÇÃO NO BRASIL, IX, . João Pessoa, 31/07 a 03/08/2012Anais eletrônicos. João Pessoa, 2012. v. 1. p. 3069-3094. Disponível em: <http://www.histedbr.fae.unicamp.br/acer_histedbr/seminario/seminariog/PDFs/4.09.pdf >. Acesso em: abr.2015.

NAHES, Semíramis. Revista FON-FON: a imagem da mulher no Estado Novo (1937-1945). Arte \& Ciência.São Paulo, 2007. 168 p. Disponível em: <http://www.unimar.br/publicacoes/ftp/miolo_Fon_Fon.pdf >. Acesso em: abr.2015.

RAINHO, Maria do Carmo Teixeira. A cidade e a moda: novas pretensões, novas distinções - Rio de Janeiro, século XIX. Brasília: Editora Universidade de Brasília, 2002. p. 172.

ROSEMBERG, Fúlvia. Mulheres educadas e a educação de mulheres. In: PINSKY, Carla Bassanezi; PEDRO, Joana Maria. (Orgs.). Nova história das mulheres no Brasil. São Paulo: Contexto, 2012. p. 333-359.

SABAT, Ruth. Gênero e sexualidade para consumo. In: LOURO, Guacira Lopes; NECKEL, Jane Felipe; GOELLNER, Silvana Vilodre (Orgs.). Corpo, gênero e sexualidade: um debate contemporâneo na educação. 3.ed. Petrópolis, RJ: Vozes, 2007, p.149-159.

SANT'ANNA, Denise Bernuzzi. Higiene e higienismo entre o Império e a República. In: DEL PRIORE, Mary, AMANTINO, Marcia (Org.). História do corpo no Brasil. São Paulo: UNESP, 2011. p.283-312. 